\title{
Reevaluation of the Strain Pressure Theory. Toward a Better Understanding the Biology of Tooth Movement
}

\author{
Reevaluación de la Teoría Presión-Tensión. Hacia una Mejor \\ Comprensión de la Biología del Movimiento Dental
}

Angela Domínguez Camacho ${ }^{1}$ \& Sergio Andres Velásquez Cujar²

DOMÍNGUEZ, C. A. \& VELÁSQUEZ, C. S. A. Reevaluation of the strain pressure theory. Toward a better understanding the biology of tooth movement. Int. J. Odontostomat., 11(2):133-140, 2017.

ABSTRACT: The aim of this report was to analyze the majority of publications referred to orthodontic movement Biological basis, principally strain- pressure theory taking account contemporaneous methodological study designs. The literature published in Pubmed from 1967 to 2014 was reviewed, in addition to well-known scientific reports that were not classified under this database like classical manuscripts since 1839. The comment items are: Limitations of animal models, Histological slices, what to watch for, Rats as an experimental model in orthodontics, Strain-pressure, the force used in these studies that fundament this theory, Reevaluation studies about strain-pressure theory in biology movement using contemporaneous models, Up to date concepts, Theory reevaluation the first step to understanding new acceleration concepts and Movement biology research, present and future. After analyzing those items we concluded: A 3D perspective is essential for a complete understanding of events in tooth movement involves two interrelated processes: the bending of alveolar bone and remodeling of the periodontal tissues. It's important to start, and acknowledge that the PDL cannot be divided into two different areas that react independently to an applied force. It's a continuous periodontal compartment in OTM, rather than a pressure side and a tension side. When an orthodontic force is applied there are two simultaneous effects that correlate. Alveolar bone flexion and remodeling of the periodontal tissues. Alveolar Bone deformation compromising the main structures (PDL, bone and cement), compression and tension can coexist in different directions. The magnitudes of compression and tension are typically different in different directions. As the majority of research and studies indicate that fundamental movement biology are made on animal models, it is important to know that their results and conclusions, under the actual evidenced based practice guidelines do not allow to make clinical decisions even if they are included on systematic reviews.

KEY WORDS: orthodontic movement, strain-pressure theory, dental movement acceleration.

\section{INTRODUCTION}

The concept that orthodontic tooth movement is dependent on the resorption and deposition of bone of the socket dates back at least to 1839 with the publication of 'The Dental Art' by Chapin Harris (Harris, 1839). It was not until the turn of the 20th century, however, that the original histological investigation that forms the foundation of our present knowledge of tooth movement, was carried out on dogs by the Swedish dentist Carl Sandstedt (1864-1904). His findings were published in 1901 (Sandstedt, 1901) as a monograph in Swedish from the Anatomy Department of the Karolinska Institute in Stockholm entitled 'Några bidrag till tandregleringens theory (Some contributions to the theory of tooth movement) (Bister \& Meikle, 2013).
Oppenheim in 1911 rejected both the pressure-tension hypothesis supported by the histological evidence of Sandstedt and the theory of bone bending advanced by Kingsley (1880) based on the elastic properties of bone. To explain his findings, Oppenheim proposed an alternative: The Law of Bone Transformation, in which the alveolar bone was completely reorganized in accordance with Wolff's Law (1892) (Oppenheim, 2007).

However, an experiment was made using a Primate (mandrill) in order to answer the following questions:- Of what nature are the changes in the bone tissue; Changes in the periodontal membrane; and

\footnotetext{
1 Department of Orthodontics, Faculty of Dentistry, Universidad del Valle, Cali, Colombia.

2 Department of Orthodontics, Institución Universitaria Colegios de Colombia (UNICOC), Cali, Colombia.
} 
Changes in the tooth itself. The experiment was made in the teeth of the ape, because their structure is nearest that of man; because the straight course of the roots assures a more direct transmission of the operational force to the bone, and because, from the anatomical standpoint, there are in the ape analogous relations of the teeth to the compact and spongy bone of the jaws of those in man. Owing to the difficulty of obtaining older animals with fully developed permanent dentitions, the experiments were conducted on the still completely firm deciduous teeth. Even though, contemporary research has shown few similarities, this study (Avery \& Simpson, 1973; Aufdemorte et al., 1993; Miller et al., 1995; Rogers \& Hixson, 1997; Weiner et al., 1999; Carr et al., 2000; Perel et al., 2007), used as reference for our clinical practice it didn't even use permanent teeth, they were deciduous, and to compare bone physiology findings, with humans, it does not show the same results as reported by a systematic review from Perel et al.

Limitations of animal models. There are two major uncertainties with using animal models to understand human diseases. Firstly, there are significant species differences in anatomy, metabolism, physiology or pharmacology caused by underlying genetic variations, including regulatory genes. This means that even minor molecular differences may be amplified when extrapolated to the cell-organ or species- levels. This variation between species can, and do regularly confound the translation of laboratory animal results to human. A second major cause of uncertainty with animal models is the nature of the conditions inflicted on them. Human illness research in animals precisely because there is a lack of knowledge about them. Most often, the cause and progression of a human condition are unknown, although the range of symptoms is understood. An animal model is usually developed on the basis of a narrow range of human symptoms, selected at a time when researchers often do not know which disease characteristics are the most important, or even which are causes rather than outcomes of illness (Knight, 2007; Langley, 2009). Recently, it has been shown that although acute inflammatory stresses from different etiologies results in highly similar genomic responses in humans, the responses in corresponding mouse models correlate poorly with the human conditions and also, one another. Among genes changed significantly in humans, the murine orthologs are close to random in matching their human counterparts (Seok et al., 2013).

Histological slices, what to watch for. Using animal histologically slices through time, orthodontics have tried to explain movement biology. It is logical and valid that this, for a long time was the only resource available to find answers related to biological fundaments. But those answers were not based on evidence practice models, thus interfering with the proper understanding of the mechanical principles dental movement acceleration. Using 5 a $10 \mu$ width histological slice (Steigman et al., 1987; Rohrer \& Schubert, 1992) limits microscopic observations to an extremely limited 2 dimension area compared to a real life 3D experience, dynamic as the cascade of cellular and molecular interactions that are involved during the application of an orthodontic force. Histological findings are not up for discussion, but the use of an animal model is; the animal model used, the time in which the animal was put away after force applied and for how long the force was applied. Animal experimentation, is limited from 4 to 16 weeks, in some cases barely days, then the results are limited to describing what did happen during this time with the use of an undetermined (excessive) force for any of the models, extremely short follow up that lacks the proper intervention of the adaptive biological response as a reaction to an applied force and also to a repeated force as it occurs in clinical orthodontics with several months of treatment.

Then to consider that a 2D animal model could clarify and explain the biology of dental movement dynamics it would be like accepting that a panoramic $X$ rays it's a much better diagnostic tool than a cone beam tomography.

Rats as an experimental model in orthodontics. The molecular techniques of reverse transcriptionpolymerase chain reaction and in situ hybridization to detect gene expression in cell and tissue sections have revolutionized tooth movement studies, particularly in the rat, which despite some anatomical and physiological shortcomings remains the experimental animal of choice (Meikle, 2006).

One of the main concerns in health science is extrapolating animal with human studies, as the vast majority of movement biology studies have used this experimental model, it is important to consider the morphological and physiological alveolar bone differences between humans and rats. It is accepted that the animal density of the alveolar bone is higher that the corresponding human structures, this has been proved on rats by densitometric testing finding lack of the narrow spaces in the alveolar bone plates. Comparatively, osseous tissue along the alveolar surface, is generally less abundant in rats, they also 
lack Osteones, thick cementoides layers formed in the apical third of the root, deposition of industrial osteophytes after a short period of experimental movement (Reitan \& Kwam, 1971). The rat's extracellular matrix contains few quantities of mucopolysaccharides and calcium balance seems to be controlled by intestinal absorption rather than by the osseous tissue itself (Ren et al., 2004). There are structural differences between periodontal fiber disposition and support structures between humans and rats (Romanos \& Bernimoulin, 1990; Romanos et al., 1991) the periodontium of continuously growing and erupting teeth displays a special arrangement. The periodontal ligament is present in the root-analog part of the tooth, which, in the rodent incisors, comprises the lingual, the mesial, and part of the distal face of the tooth. The crown-analog part, at the labial and part of the distal face where the enamel is present, has a connective tissue between the enamel organ and the alveolar bone, termed the enamel-related periodontium. This tissue corresponds to the dental follicle related to the crown of teeth, such as rat molars, while in an intraosseous position. In the teeth of limited growth, the crown-related dental follicle disappears after the tooth emerges in the oral cavity and its role in promoting bone resorption for the development of the eruption pathway is well established. In continuously growing teeth, the dental follicle is renewed as the tooth grows and erupts (Marks \& Cahill, 1987; Merzel \& Salmon, 2008). Bone turnover, it's also different, comparing rats and human alveolar bone density has a direct effect on the amount of dental movement. Also, bone turnover, is faster in rats, and locally there are some differences. The bone turnover dynamics adjacent to maxillary first molars present predominantly remodeling on the distal surface in young rats (1 month) and older (3 months) and modeling on the mesial surface only in the young rats. Alveolar bone on the mesial surface of the molars it's more compact, and during orthodontic movement towards this side this characteristic could slower it (King et al., 1995). This characteristic is representative of the molar physiological movement toward distal that has been reported to be between 6.7 and 7.7 microns a day (King et al., 1991), adding to a continuous eruption of the incisors, could facilitate to create an inexact measure of the mesial movement, and a poor incisor anchorage causing changes in the force direction.

Strain - pressure, the force used in studies that fundament this theory. The current concept of optimal force is based on the hypothesis that a force of a certain magnitude and characteristics would be capable of producing a maximum rate of tooth movement without tissue damage and with maximum patient comfort (Proffit, 1999), Schwarz in 1932, defines it as "The force leading to a change in tissue pressure that approximated the capillary vessels' blood pressure, thus preventing their occlusion in the compressed periodontal ligament". Oppenheim in 1942, conceptualized as "the minimum load necessary to produce movement", and from Reitan, in 1967, A biologically accepted force has to be light.

\section{But what it's a light force in orthodontics?}

Human and animal reports show arbitrary forces used under the same concept. Some study samples show a wider range of force for different experimental models, as Ren et al. (2003) sample about the optimal level forces in a systematic review. Forces applied to cats, dogs Harris, Guinea pigs, rabbits, monkeys, and rats had a wider range between 10 and $500 \mathrm{gf}$ for the different types of movement, for some research $10 \mathrm{gf}$ is a light force but for others $50-200 \mathrm{gf}$ is the same light force (Dellinger, 1967; Utley, 1968; Fortin, 1971; Botin \& Storey, 1973; Mitchell et al., 1973; Steigman \& Michaeli, 1981; Steiner et al., 1981; Bridges et al., 1988; Gibson et al., 1992; Pilon et al., 1996; van Leeuwen et al., 1999). In the same publication (Ren et al.), they included 12 human studies to analyze a meta-analysis of the literature concerning the optimal force or range of forces for orthodontic tooth movement. Eight studies dealt with canine retraction. A wide range of initial forces $(18-1500 \mathrm{cN})$ were used in these studies. The articles that reported on premolar tipping using forces from 50 to $200 \mathrm{cN}$ (Owman-Moll et al., 1996), and two articles reported on molar tipping using forces from 100 to $500 \mathrm{cN}$ (Andreasen \& Zwanziger, 1980; Gu et al., 1999). The number and the homogeneity of the included human studies were too limited to enable a meta-analysis.

From the included studies Iwasaki et al. (2000) stands out as they performed an efficient canine retraction only using $18 \mathrm{grf}$, his study also reported that in order to properly calculate the force needed to move a canine the root length should be measured against movement and an interfocal elliptic distance at a cervical level, not diameter as the root it is never perfectly round.

Only up to the year 2000 , it was reported that an optimal light force, to properly move a canine without compromising its final position, on the three planes of space was obtained only with $18 \mathrm{gr}$, this means that 
any force level above this, used prior or in future studies cannot be qualified as a light force. It's very important to clarify that if it is possible to properly move a human canine with $18 \mathrm{gr}$ then it's impossible to consider $50 \mathrm{gr}$ an adequate force to move a rat molar.

Reevaluation studies about strain- pressure theory in biology movement contemporaneous models. Vercelli et al. (2008) claimed that: "strain - pressure theory is omnipresent in orthodontics, nonetheless due to a lack of structure characterization, there's no unification about the mechanism that relates stimulus to bone response" so in their study their objective was to analyze predominant directions on the strainpressure phenomena at the alveolar bone. When simulating canine distalization by transferring and inclination to a premolar site with a finite element model, the authors found that the alveolar wall presents a deformation due to the dental transferring movement, even in the adjacent alveolus, and they concluded that in the same region as the root, PDL, and bone a predominant strain load can be happening and a pressure load at the same time in other structure. At a given point in a structure, compression and tension can coexist in different directions. The magnitudes of compression and tension are typically different in different directions. Because of direction swaps between principal stresses, previously published data of only stress magnitude plots can be confusing and perhaps impossible to understand or correlate with biological responses. To prevent ambiguities, a reference to a principal stress should include not only the structure, but also its predominant direction. Combined stress magnitude and direction results suggest that the PDL is the initiator of mechano transduction.

Cattaneo et al. (2009) considered that According to the classical OTM theories, symmetric zones of compression and tension are present in the periodontium, but these do not consider the complex mechanical properties of the PDL, the alveolar structures' morphology, and the magnitude of the force applied. They employed finite element method to describe orthodontic charge transfer from the tooth to the alveolus, and also to establish the influence of force magnitude of load distribution and deflection of the alveolar support structures. Samples from Human jaw segments obtained from autopsy were microCTscanned and sample-specific finite element (FE) models were generated. Transferring, tipping forces and the influence of magnitude on load distribution ranging from 50 to $400 \mathrm{gf}$ were evaluated.
Among the results, they found that an alveolar deformation occurs when a longitudinal and lateral load is applied producing an asymmetric concavity with fiber deformation in the alveolar wall. The authors concluded that after a regular orthodontic load osseous alveolar remodeling can't be based on a simple but generally accepted model that resorption it's caused by compression and bone formation by tension. Bildt et al. (2009) taking into account that Matrix metalloproteinases (MMPs) degrade the extracellular matrix during re-modelling, while their activity is regulated by the tissue inhibitors of metalloproteinases (TIMPs), made a study to find the differences in MMP and TIM levels in crevicular fluid corresponding to the bone resorption and apposition sides on orthodontically moved teeth and compare them to a control group. The sample was 8 patients with premolar extractionsapplying a $150 \mathrm{gf}$ force to distalize the canine. In general, higher levels of MMPs and TIMPs were found at both the resorption and apposition sides compared with the control teeth. This probably reflects a general increase on the bone remodeling during dental movement, and does not specify a clear side of bone remodeling nor apposition.

Up to date concepts. When an orthodontic force it's applied there are two simultaneous effects that correlate. Alveolar bone flexion and remodeling of the periodontal tissues. Alveolar Bone deformation compromising the main structures (PDL, bone, and cement), compression and tension can coexist in different directions. The magnitudes of compression and tension are typically different in different directions. These Combined, stress magnitude and direction results suggest that the PDL is the initiator of mechanotransduction. In general, the bone reaction to orthodontic tooth movement is described using the two terms "modeling "and "remodeling". However, these two terms are sometimes confused by orthodontists. Basically, "modeling" is the sculpting mechanism that uses the raw material of bone growth to shape structures, whereas "remodeling" is the mechanism underlying the lifelong skeletal turnover and maintenance. Modeling and remodeling can coexist during bone growth. Tooth movements resulting from orthodontic forces provide a mechanical stimulus that induces biological responses, and the transformation involves both bone modeling and remodeling (Chang et al., 2012).

In essence bone remodeling is orchestrated by cells of osteoblast lineage and involves a complex network of cell-to-cell and cell-to-matrix interactions involving systemic hormones, locally produced cytokines, 
growth factors, many of which are sequestrated within the bone matrix, as well as the mechanical environment of cells (Patil et al., 2013). Orthodontists work in a unique biological environment, wherein applied forces engender remodeling of both mineralized and non-mineralized paradental tissues, including the associated blood vessels and neural elements (Krishnan \& Davidovitch, 2009). It's the neural level stimulus that produces neuropeptide release. Among them, an initial trigger for a biochemical cascade which comprises the activation of various types of PDL cells: P substance (Nicolay et al., 1990).

$P$ substance, not only increases on the PDL in response to orthodontic force, but also at the pulp tissue, being responsible for pain felt during treatment on these structures (Nicolay et al., 1991) there are two physiological processes that happened at the same time in which this neuropeptide has an important role. SP is a multifunctional neuropeptide that transmits pain signals, regulates the immune system, and may modulate bone metabolism. Including osteoblastic bone formation and osteoclastic bone resorption. SP increased HO-1 (heme oxygenase-1) and osteogenic differentiation in concentration- and time-dependent manners, as determined by Osteopontin (OPN), Osteonectin (ON), Osteocalcin (OCN), alkaline phosphatase (ALP) and bone Sialoprotein (BSP) expression (Cho et al., 2008; Kook et al., 2009). In relation to the bone resorption process, $\mathrm{P}$ stimulated the receptor activator of nuclear factor kappa B ligand (RANKL) in human osteoclast precursors (Sohn, 2005). Being the system RANKRANKL-OPG in charge of osseous metabolism regulation (Theoleyre et al., 2004). SP increase as the result of a force applied during orthodontic treatment may modulate osteoblastic cell differentiation of human IPDL cells through a mechanism involving $\mathrm{HO}-1$ expression (Cho et al.). A rise on osteoblast differentiation will allow a higher RANKL expression and thereby an increase in the activation of RANK-RANKL system with a decrease on OPG (Osteoprotegerin) (Kook et al.) levels, these promotes Osteoclastogénesis, as reported by Nishijima et al. (2006), showing a RANKL rise and an OPG diminution during orthodontic force application measured in crevicular fluid.

Theory reevaluation, the first step to understanding new acceleration concepts. It's ok to develop animal studies on rats as it favors a large sample, is cheaper than other study models and antibodies for the majority of cellular and molecular biology techniques are already available (Ren et al.) it's important to emphasize to which level we want to comprehend the complex chain of biological reactions that developed as a tooth is moved with an orthodontic force, this cannot be executed in such different study models as rats, monkeys or Dogs. The main idea that strain- pressure sides are generated on the PDL, its strongly embedded in the orthodontist subconscious, and stills plays an important role in our own ideas, as we try to advance in the understanding of this complex biological process (Meikle). Orthodontists work in a unique biological environment, wherein applied forces engender remodeling of both mineralized and non-mineralized paradental tissues. Identifying and understanding events that affect the sequence, timing, and significance of factors that determine the nature of the biological response of each paradental tissue to an applied force, orthodontists might be able to accelerate or decelerate tooth movement by adding adjuvant methods, whether physical, chemical, or surgical (Krishnan \& Davidovitch).

It's important to start and acknowledge that the PDL cannot be divided into two different areas that react independently to a force applied. It's a continuous periodontal compartment in OTM, rather than a pressure side and a tension side (Iglesias-Linares et al., 2012). This is why acceleration methods cannot focus on promoting biological events, considering two different reaction areas, rather than achieve a wholesome dento alveolar bone remodeling.

Movement acceleration methods should not emphasize in promoting Osteoclastogenesis more than Osteoblastogenesis. Osteoblast proliferation methods, as LLL allow RANK-RANKL-OPG system activation, thereby accelerating osseous metabolism, promoting acceleration while targeting osteoblast proliferation using auto regulatory mechanisms that induced differentiation and activation of osteoclasts via effects on the RANK system of signaling, as reported by Aihara et al. (2006). In the current methods, dento alveolar bone it's the key for initialization of the mechanotrasduction of the load on the tooth more than the periodontal ligament.

Movement biology research, present and future. As the majority of research and studies that fundament movement biology are made on animal models, it's important to know that their results and conclusions, under the actual evidenced based practice guidelines do not allow to make clinical decisions even if they are included in systematic reviews. When properly conducted, Systematic Reviews (SRs) and Meta analyses are ranked high in the pyramid of evidence, and their results can influence clinical decisions and serve as a foundation for evidence-based practice 
guidelines. However, SRs can be prone to biases originating from the poor quality of the included studies, heterogeneity between studies, and possible publication biases. Then to include in a systematic review animal studies, it takes the article apart from any clinical use an obviously does not provide any conclusions about human effects. Also, these types of studies are not included on the evidence scale or are classified bellow expert opinions (Evidence-Based Medicine Working Group, 1992; Sackett et al., 1996; Burns et al., 2001; Sygouros \& Acar, 2013). Actual biological research should be focussed to a methodology that allows the understanding of the complex cellular and molecular biology that takes place during force application on the tooth surrounding tissues. The $\mathrm{Ct}$ method allows to evaluate bone quality before and after orthodontic treatment with or without movement acceleration techniques (Chang et al., 2012; Shoreiba et al., 2012). And crevicular fluid test that allows us to evaluate different biomarkers levels (d'Apuzzo et al., 2013):

-Biomarkers of inflammation: Interleukins (IL-1b, IL6, IL-8) Tumor Necrosis factors (TNF- $\alpha$ ) Colonystimulating factors (M-CSF, G-CSF, GM-CSF) Growth factors (VEGF) Arachidonic acid derivates and prostaglandins (PGE) Calcitonin gene related peptide (CGRP) Substance P Neutrophil alkaline phosphatase (ALP).

-Biomarkers of bone resorption: Receptor activator of nuclear factor kappa-B (RANK) Receptor activator of nuclear factor kappa-B ligand (RANKL) Biomarkers of cell death Caspase-1 B-glucuronidase (bG) Aspartate aminotransferase (AST) lactate dehydrogenase (LDH.

-Biomarkers of bone deposition and mineralization: Osteoprotegerin (OPG) Bone alkaline phosphatase (ALP).

All these biomarkers can be employed before, during and after induced dental movement, to better understand what's happening in the PDL, and can be used to benefit movement acceleration methods.

\section{CONCLUSIONS}

A $3 \mathrm{D}$ perspective is essential for a complete understanding of events in tooth movement involves two interrelated processes: the bending of alveolar bone and remodeling of the periodontal tissues. It's important to start and acknowledge that the PDL cannot be divided into two different areas that react independently to a force applied. It's a continuous periodontal compartment in OTM, rather than a pressure side and a tension side. - When an orthodontic force it's applied there are two simultaneous effects that correlate. Alveolar bone flexion and remodeling of the periodontal tissues. Alveolar Bone deformation compromising the main structures (PDL, bone and cement), compression and tension can coexist in different directions. The magnitudes of compression and tension are typically different in different directions. These Combined, stress magnitude and direction results suggest that the PDL is the initiator of mechanotransduction. - As the majority of research and studies that fundament movement biology are made on animal models, it's important to know that their results and conclusions, under the actual evidenced based practice guidelines do not allow to make clinical decisions even if they are included on systematic reviews. - Movement acceleration methods should not emphasize in promoting Osteoclastogenesis more than Osteoblastogenesis. In the current methods, dento alveolar bone it's the key for initialization of the mechanotrasduction of the load on the tooth more than the periodontal ligament.

DOMÍNGUEZ, C. A. \& VELÁSQUEZ, C. S. A. Reevaluación de la teoría Presión-Tensión. Hacia una mejor comprensión de la biología del movimiento dental. Int. J. Odontostomat., 11(2):133-140, 2017.

RESUMEN. El objetivo de esta revisión es analizar la mayoría de las publicaciones relacionadas a la fundamentación sobre el movimiento de ortodoncia, principalmente la teoría presión-tensión, teniendo en cuenta los diseños de estudios metodológicos contemporáneos. Se revisó la literatura publicada en la base de datos de MEDLINE, 1967-2013, además de los informes conocidos que no fueron clasificados en esta base de datos como manuscritos clásicos desde 1839. Los temas principales en los que se divide el artículo son: Limitaciones de los modelos animales, cortes histológicos, las ratas como modelo experimental en ortodoncia, la fuerza utilizada en los estudios que fundamentan esta teoría, reevaluación sobre los estudios de la teoría presión -tensión en modelos contemporáneos, conceptos actuales en biología del movimiento, reevaluación de la teoría: el primer paso para entender los nuevos métodos en aceleración del movimiento, conceptos e investigaciones en biología del movimiento: presente y futuro. Una perspectiva 3D es esencial para una comprensión completa de los acontecimientos. El movimiento dental implica dos procesos interrelacionados: la curvatura del hueso alveolar y la remodelación de los tejidos periodontales. Es importante empezar, y reconocer que el PDL no puede 
ser dividido en dos áreas diferentes que reaccionan de forma independiente a una fuerza aplicada. Está en un compartimiento continuo periodontal , en lugar de un lado de presión y un lado de tensión. Al aplicar una fuerza de ortodoncia hay dos efectos simultáneos: la flexión del hueso Alveolar y la remodelación de los tejidos periodontales. La deformación del hueso compromete las estructuras principales (PDL, hueso y cemento) y la compresión y la tensión pueden coexistir en diferentes direcciones.

PALABRAS CLAVE: Movimiento Ortodóncico, Teoría Presión-Tensión, Aceleración del movimiento dental.

\section{REFERENCES}

Aihara, N.; Yamaguchi, M. \& Kasai, K. Low-energy irradiation stimulates formation of osteoclast-like cells via RANK expression in vitro. Lasers Med. Sci., 21(1):24-33, 2006.

Andreasen, G. F. \& Zwanziger, D. A clinical evaluation of the differential force concept as applied to the edgewise bracket. Am. J. Orthod., 78(1):25-40, 1980.

Aufdemorte, T. B.; Boyan, B. D.; Fox, W. C. \& Miller, D. Diagnostic tools and biologic markers: Animal models in the study of osteoporosis and oral bone loss. J. Bone Miner. Res., 8 (Suppl. 2):S529-34, 1993.

Avery, B. E. \& Simpson, D. M. The baboon as a model system for the study of periodontal disease: clinical and light microscopic observations. J. Periodontol., 44(11):675-86, 1973.

Bildt, M. M.; Bloemen, M.; Kuijpers-Jagtman, A. M. \& Von den Hoff, J. W. Matrix metalloproteinases and tissue inhibitors of metalloproteinases in gingival crevicular fluid during orthodontic tooth movement. Eur. J. Orthod., 31(5):529-35, 2009.

Bister, D. \& Meikle, M. C. Re-examination of 'Einige Beitrage zur Theorie der Zahnregulierung' (Some contributions to the theory of the regulation of teeth) published in 1904-1905 by Carl Sandstedt. Eur. J. Orthod., 35(2):160-8, 2013.

Botin, P. S. \& Storey, E. Bone changes associated with the application of very low forces to incisor teeth in the guinea-pig. Aust. Dent. J., 18(4):240-5, 1973.

Bridges, T.; King, G. \& Mohammed, A. The effect of age on tooth movement and mineral density in the alveolar tissues of the rat. Am. J. Orthod. Dentofacial Orthop., 93(3):245-50, 1988.

Burns, P. B.; Rohrich, R. J. \& Chung, K. C. The levels of evidence and their role in evidence-based medicine. Plast. Reconstr. Surg., 128(1):305-10, 2001

Carr, A. B.; Gerard, D. A. \& Larsen, P. E. Histomorphometric analysis of implant anchorage for 3 types of dental implants following 6 months of healing in baboon jaws. Int. J. Oral Maxillofac. Implants, 15(6):785-91, 2000

Cattaneo, P. M.; Dalstra, M. \& Melsen, B. Strains in periodontal ligament and alveolar bone associated with orthodontic tooth movement analyzed by finite element. Orthod. Craniofac. Res., 12(2):120-8, 2009.

Chang, H. W.; Huang, H. L.; Yu, J. H.; Hsu, J. T.; Li, Y. F. \& Wu, Y. F. Effects of orthodontic tooth movement on alveolar bone density. Clin. Oral Investig., 16(3):679-88, 2012.

Cho, Y. M.; Suh, C. H.; Chun, S. W.; Kim, E. C. \& Kang, K. H. Effects of substance $\mathrm{P}$ on mineralization markers and heme oxygenase1. Expression in human immortalized periodontal ligament cells. Int. J. Oral Biol., 33(4):131-5, 2008.

d'Apuzzo, F.; Cappabianca, S.; Ciavarella, D.; Monsurrò, A.;
Silvestrini-Biavati, A. \& Perillo, L. Biomarkers of periodontal tissue remodeling during orthodontic tooth movement in mice and men: overview and clinical relevance. Scientific World J., 2013:105873, 2013.

Dellinger, E. L. A histologic and cephalometric investigation of premolar intrusion in the Macaca speciosa monkey. Am. J. Orthod., 53(5):325-55, 1967.

Evidence-Based Medicine Working Group. Evidence-based medicine. A new approach to teaching the practice of medicine. JAMA, 268(17):2420-5, 1992.

Fortin, J. M. Translation of premolars in the dog by controlling the moment-to-force ratio on the crown. Am. J. Orthod., 59(6):54151,1971

Gibson, J. M.; King, G. J. \& Keeling, S. D. Long-term orthodontic tooth movement response to short-term force in the rat. Angle Orthod., 62(3):211-5, 1992.

Gu, G.; Lemery, S. A. \& King, G. J. Effect of appliance reactivation after decay of initial activation on osteoclasts, tooth movement, and root resorption. Angle Orthod., 69(6):515-22, 1999.

Harris, C. A. The Dental Art. A Practical Treatise On Dental Surgery. Baltimore, Armstrong \& Berry, 1839. pp.104.

Iglesias-Linares, A.; Yañez-Vico, R. M.; Moreno-Fernandez, A. M.; Mendoza-Mendoza, A. \& Solano-Reina, E. Corticotomy-assisted orthodontic enhancement by bone morphogenetic protein-2 administration. J. Oral Maxillofac. Surg., 70(2):e124-32, 2012.

Iwasaki, L. R.; Haack, J. E.; Nickel, J. C. \& Morton, J. Human tooth movement in response to continuous stress of low magnitude. Am. J. Orthod. Dentofacial Orthop., 117(2):175-83, 2000.

King, G. J.; Keeling, S. D., McCoy, E. A. \& Ward, T. H. Measuring dental drift and orthodontic tooth movement in response to various initial forces in adult rats. Am. J. Orthod. Dentofacial Orthop., 99(5):456-65, 1991.

King, G. J.; Latta, L.; Rutenberg, J.; Ossi, A. \& Keeling, S. D. Alveolar bone turnover in male rats: site- and age-specific changes. Anat. Rec., 242(3):321-8, 1995.

Knight, A. Systematic reviews of animal experiments demonstrate poor human clinical and toxicological utility. Altern. Lab. Anim., 35(6):641-59, 2007.

Kook, Y. A.; Lee, S. K.; Son, D. H.; Kim, Y.; Kang, K. H.; Cho, J. H.; Kim, S. C.; Kim, Y. S.; Lee, H. J.; Lee, S. K. \& Kim, E. C. Effects of substance $P$ on osteoblastic differentiation and heme oxygenase-1 in human periodontal ligament cells. Cell Biol. Int., 33(3):424-8, 2009.

Krishnan, V. \& Davidovitch, Z. On a path to unfolding the biological mechanisms of orthodontic tooth movement. J. Dent. Res., 88(7):597-608, 2009.

Langley, G. La validité de l'expérimentation animale en recherche médicale. Rev. Semest. Droit Anim., 1:161-8, 2009.

Marks, S. C. Jr. \& Cahill, D. R. Regional control by the dental follicle of alterations in alveolar bone metabolism during tooth eruption. J. Oral Pathol., 16(4):164-9, 1987.

Meikle, M. C. The tissue, cellular, and molecular regulation of orthodontic tooth movement: 100 years after Carl Sandstedt. Eur. J. Orthod., 28(3):221-40, 2006.

Merzel, J. \& Salmon, C. R. Growth and the modeling/remodeling of the alveolar bone of the rat incisor. Anat. Rec. (Hoboken), 291(7):827-34, 2008.

Miller, D. R.; Aufdemorte, T. B.; Fox, W. C.; Waldrop, T. C.; Mealey, B. L. \& Brunsvold, M. A. Periodontitis in the baboon: a potential model for human disease. J. Periodontal Res., 30(6):404-9, 1995.

Mitchell, D. L.; Boone, R. M. \& Ferguson, J. H. Correlation of tooth movement with variable forces in the cat. Angle Orthod., 43(2):154-61, 1973.

Nicolay, O. F.; Davidovitch, Z.; Shanfeld, J. L. \& Alley, K. Substance $\mathrm{P}$ immunoreactivity in periodontal tissues during orthodontic tooth movement. Bone Miner., 11(1):19-29, 1990. 
Nicolay, O.; Shanfeld, J.; Davidovitch, Z. \& Alley, K. SP immunoreactivity in the dental pulp and periodontium during tooth movement. Ann. N. Y. Acad. Sci., 632:452-4, 1991.

Nishijima, Y.; Yamaguchi, M.; Kojima, T.; Aihara, N.; Nakajima, R. \& Kasai, K. Levels of RANKL and OPG in gingival crevicular fluid during orthodontic tooth movement and effect of compression force on releases from periodontal ligament cells in vitro. Orthod. Craniofac. Res. , 9(2):63-70, 2006.

Oppenheim, A. Human tissue response to orthodontic intervention of short and long duration. Am. J. Orthod. Dentofacial Orthop., 28(5):263-301, 1942.

Oppenheim, A. Tissue changes, particularly of the bone, incident to tooth movement. Eur. J. Orthod., 29:i2-15, 2007.

Owman-Moll, P.; Kurol, J., \& Lundgren, D. The effects of a four-fold increased orthodontic force magnitude on tooth movement and root resorptions. An intra-individual study in adolescents. Eur. J. Orthod., 18(3):287-94, 1996.

Patil, A. K.; Shetty, A. S.; Setty, S. \& Thakur, S. Understanding the advances in biology of orthodontic tooth movement for improved ortho-perio interdisciplinary approach. J. Indian Soc. Periodontol., 17(3):309-18, 2013.

Perel, P.; Roberts, I.; Sena, E.; Wheble, P.; Briscoe, C.; Sandercock, P.; Macleod, M.; Mignini, L. E. ; Jayaram, P. \& Khan, K. S. Comparison of treatment effects between animal experiments and clinical trials: systematic review. BMJ, 334(7586):197, 2007.

Pilon, J. J.; Kuijpers-Jagtman, A. M. \& Maltha, J. C. Magnitude of orthodontic forces and rate of bodily tooth movement. An experimental study. Am. J. Orthod. Dentofacial Orthop., 110(1):16-23, 1996.

Proffit, W. R. Contemporary Orthodontics. St. Louis, Mosby, 1999. pp.296-325.

Reitan, K. \& Kvam, E. Comparative behavior of human and animal tissue during experimental tooth movement. Angle Orthod., 41(1):1-14, 1971.

Reitan, K. Clinical and histologic observations on tooth movement during and after orthodontic treatment. Am. J. Orthod., 53(10):72145, 1967.

Ren, Y.; Maltha, J. C. \& Kuijpers-Jagtman, A. M. Optimum force magnitude for orthodontic tooth movement: a systematic literature review. Angle Orthod., 73(1):86-92, 2003.

Ren, Y.; Maltha, J. C. \& Kuijpers-Jagtman, A. M. The rat as a model for orthodontic tooth movement--a critical review and a proposed solution. Eur. J. Orthod., 26(5):483-90, 2004.

Rogers, J. \& Hixson, J. E. Baboons as an animal model for genetic studies of common human disease. Am. J. Hum. Genet., 61(3):489-93, 1997.

Rohrer, M. D. \& Schubert, C. C. The cutting-grinding technique for histologic preparation of undecalcified bone and bone-anchored implants. Improvements in instrumentation and procedures. Oral Surg. Oral Med. Oral Pathol., 74(1):73-8, 1992.

Romanos, G. E. \& Bernimoulin, J. P. Collagen as a basic element of the periodontium: immunohistochemical aspects in the human and animal. 1. Gingiva and alveolar bone. Parodontologie, 1(4):363-75, 1990.

Romanos, G. E.; Schröter-Kermani, C. \& Bernimoulin, J. P. Collagen as a basic element of the periodontium: immunohistochemical aspects in the human and animals. 2. Cementum and periodontal ligament. Parodontologie, 2(1):47-59, 1991.

Sackett, D. L.; Rosenberg, W. M.; Gray, J. A.; Haynes, R. B. \& Richardson, W. S. Evidence based medicine: what it is and what it isn't. BMJ, 312(7023):71-2, 1996.

Schwarz, A. M. Tissue changes incident to orthodontic tooth movement. Int. J. Orthod., 18:331-52, 1932.

Seok J.; Warren, H. S.; Cuenca, A. G.; Mindrinos, M. N.; Baker, H. V.; Xu, W.; Richards, D. R.; McDonald-Smith, G. P.; Gao, H.; Hennessy, L.; Finnerty, C. C.; López, C. M.; Honari, S.; Moore,
E. E.; Minei, J. P.; Cuschieri, J.; Bankey, P. E.; Johnson, J. L.; Sperry, J.; Nathens, A. B.; Billiar, T. R.; West, M. A.; Jeschke, M. G.; Klein, M. B.; Gamelli, R. L.; Gibran, N. S.; Brownstein, B. H.; Miller-Graziano, C.; Calvano, S. E.; Mason, P. H.; Cobb, J. P.; Rahme, L. G.; Lowry, S. F.; Maier, R. V.; Moldawer, L. L.; Herndon, D. N.; Davis, R. W.; Xiao, W.; Tompkins, R. G. \& Inflammation and Host Response to Injury, Large Scale Collaborative Research Program. Genomic responses in mouse models poorly mimic human inflammatory diseases. Proc. Natl. Acad. Sci. U. S. A., 110(9):3507-12, 2013.

Shoreiba, E. A.; Salama, A. E.; Attia, M. S. \& Abu-Seida, S. M. Corticotomy-facilitated orthodontics in adults using a further modified technique. J. Int. Acad. Periodontol., 14(4):97-104, 2012.

Sohn, S. J. Substance $P$ upregulates osteoclastogenesis by activating nuclear factor kappa B in osteoclast precursors. Acta Otolaryngol., 125(2):130-3, 2005.

Steigman, S. \& Michaeli, Y. Experimental intrusion of rat incisors with continuous loads of varying magnitude. Am. J. Orthod., 80(4):429-36, 1981.

Steigman, S.; Michaeli, Y. \& Weinreb, M. Jr. Structural changes in the dental and periodontal tissues of the rat incisor following application of orthodontic loads. Am. J. Orthod. Dentofacial Orthop., 91(1):49-56, 1987.

Steiner, G. G.; Pearson, J. K. \& Ainamo, J. Changes of the marginal periodontium as a result of labial tooth movement in monkeys. $J$. Periodontol., 52(6):314-20, 1981.

Sygouros, A. \& Acar, A. Evidence-based orthodontics: Appraisal of the methodologies of systematic reviews and meta-analyses in controversial areas of orthodontics. J. World Fed. Orthod., 2(3):e117-22, 2013.

Theoleyre, S.; Wittrant, Y.; Tat, S. K.; Fortun, Y.; Redini, F. \& Heymann, $D$. The molecular triad OPG/RANK/RANKL: involvement in the orchestration of pathophysiological bone remodeling. Cytokine Growth Factor Rev., 15(6):457-75, 2004.

Utley, R. K. The activity of alveolar bone incident to orthodontic tooth movement as studied by oxytetracycline-induced fluorescence. Am. J. Orthod., 54(3):167-201, 1968.

van Leeuwen, E. J.; Maltha, J. C. \& Kuijpers-Jagtman, A. M. Tooth movement with light continuous and discontinuous forces in beagle dogs. Eur. J. Oral Sci., 107(6):468-74, 1999.

Viecilli, R. F.; Katona, T. R.; Chen, J.; Hartsfield, J. K. Jr. \& Roberts, W. E. Three-dimensional mechanical environment of orthodontic tooth movement and root resorption. Am. J. Orthod. Dentofacial Orthop., 133(6):791.e11-26, 2008.

Weiner, S.; Traub, W. \& Wagner, H. D. Lamellar bone: structurefunction relations. J. Struct. Biol., 126(3):241-55, 1999.

Correspondence author:

Angela Domínguez Camacho, DDS

Orthodontist, Professor, Faculty of Dentistry

Universidad Del Valle

Calle 4a.B \# 36-00

Cali

COLOMBIA

E-mail: angela.Dominguezc@gmail.com

Received: 07-07-2016

Accepted: 06-04-2017 